\title{
Instantaneous Minimum Fuel Consumption Control for Parallel Hybrid Hydraulic Excavator
}

\author{
Xu Miao ${ }^{*},{ }^{,}$Zhao Dingxuan ${ }^{1}, \mathrm{Ni}$ Tao ${ }^{1}$ and Wang Yao ${ }^{1,2}$ \\ ${ }^{1}$ College of Mechanical Science and Engineering, Jilin University, Changchun, Jilin, 130022, P.R. China \\ ${ }^{2}$ College of Mechanical Engineering, Beihua University, Jilin, Jilin, 132021, P.R. China
}

\begin{abstract}
Hybrid excavator control strategy based on rules optimizes the specific fuel consumption only to determine engine operating point in the perspective of qualitative analysis, it is not sufficient to reduce the excavator fuel consumption because of ignoring the affect of engine power output. In this paper, an instantaneous minimum fuel consumption control strategy for hybrid power-train is proposed, strategy determines the ideal operating point taking both the main influence factors of fuel consumption into consideration, the ultra-capacitor energy variation which is caused by the motor power output is converted to the equivalent fuel consumption and included in the current power-train fuel consumption. The output torque combination of the engine and motor which minimize the current fuel consumption is adopted. The bench test results validate that the engine is $12 \%$ fuel saving on average after optimizing, and at the same time the ultra-capacitor energy is effectively maintained.
\end{abstract}

Keywords: Hydraulic excavator, hybrid, minimum fuel consumption, optimization.

\section{INTRODUCTION}

Hydraulic excavator has a large market maintenance and its market demand is steadily growing because of their multiple functions and strong adaptability [1]. As it is well known, the excavator load changes considerably which leads to a low fuel efficiency. To increase its fuel efficiency, the major international excavator research institutions and manufacturers intend to integrate the hybrid technology to excavators, which has been successfully implemented to automobiles [2-4]. This hybrid technology uses multi power sources to provide the required power. The key problem in hybrid excavator design is to develop suitable control strategy $[5,6]$. Hitachi Construction Machinery, Komatsu and CAT were the first to begin research in this field [7-10]. Komatsu has produced the first hybrid hydraulic excavator prototype in 2004.

In China under the field of hybrid excavators, Zhejiang University holds the leading research position and put forward a series of control strategy based on rules. A constant operating point control strategy for a $5 \mathrm{t}$ parallel hybrid excavator with ultra capacitor is presented in [11]. This control strategy is easy to apply, but its load adaptability is not sufficient well. Then to improve its load adaptability, a dynamic operating point control strategy is proposed in [1] which optimized the ultra-capacitor efficiency. D. Wang developed a speed adaptive control strategy based on operating condition analysis in [12]. This control strategy, however, reduces the operation efficiency to some extent. In [13] a quasi-constant operating point control strategy is proposed for $20 \mathrm{t}$ hydraulic excavator with parallel hybrid system. All these control strategies which aim to improve the engine fuel efficiency are called specific fuel consumption strategy. The minimization of the specific fuel consumption, however, does not guarantee the reduction of fuel consumption because it depends both on the specific fuel consumption and the effective output power. To avoid this drawback, in this paper an instantaneous minimum fuel control strategy is proposed. In this strategy, it is the fuel consumption not the specific fuel consumption is minimized. Finally, the proposed control strategy is validated on an excavator parallel hybrid power-train test bench.

\section{ENGINE EFFICIENCY EVALUATION INDEX}

One of the important measurement for engine economic performance is the following defined specific fuel consumption $g_{e}$

$g_{e}=\frac{G_{T}}{N_{e}} \times 10^{3}[\mathrm{~g} / \mathrm{kw} \cdot \mathrm{h}]$

$G_{T}$--- the fuel consumption per hour $[\mathrm{kg} / \mathrm{h}]$;

$N_{e}$--- the effective output power [kw];

The engine operating point control strategy optimizes ge in order to reduce the fuel consumption. However, the minimization of ge doesn't guarantee that the fuel consumption will be reduced because the fuel consumption depends not only on the specific fuel consumption but also on the engine output power. Consider the load characteristics of the engine used in this research, shown in Fig. (1). The specific fuel consumption ge is the same in points $\mathrm{A}$ and $\mathrm{B}$, but the corresponding fuel consumptions are not equal 
because in these points the output power is different. Thus optimizing only ge, one may not achieve the goal of reducing the fuel consumption.

In this paper we propose an instantaneous minimum fuel control strategy in which both specific fuel consumption and output power are considered and optimized.

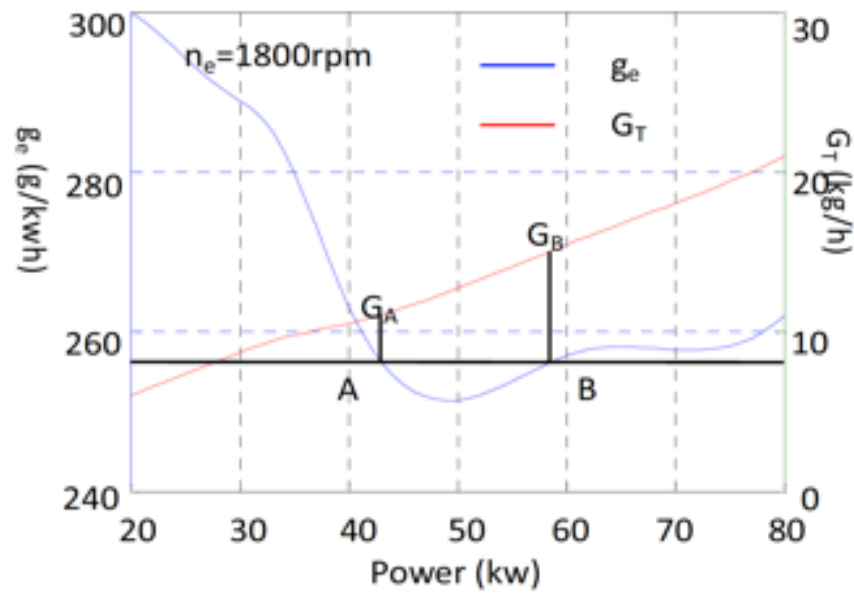

Fig. (1). Engine load characteristics.

\section{INSTANTANEOUS MINIMUM FUEL CONTROL STRATEGY}

In this paper a $20 \mathrm{t}$ parallel hybrid hydraulic excavator is considered. As shown in Fig. (2), the engine, ISG motor and pump are connected coaxially, and the ISG motor, motor controller and ultra-capacitor are connected electrically. The engine supplies most of the power which is needed for driving the pump and the ISG motor. The ISG motor is an energy conversion device and depending on load requirements it serves either as an electric motor or as a generator. And the role of the ultra-capacitor storage element is to control the engine high fuel consumption efficiency in the buffer zone for power. In order to ensure the ultracapacitor working effectively, one needs to maintain its state of charge in a reasonable limit in order to ensure the efficient functioning of the capacitor.

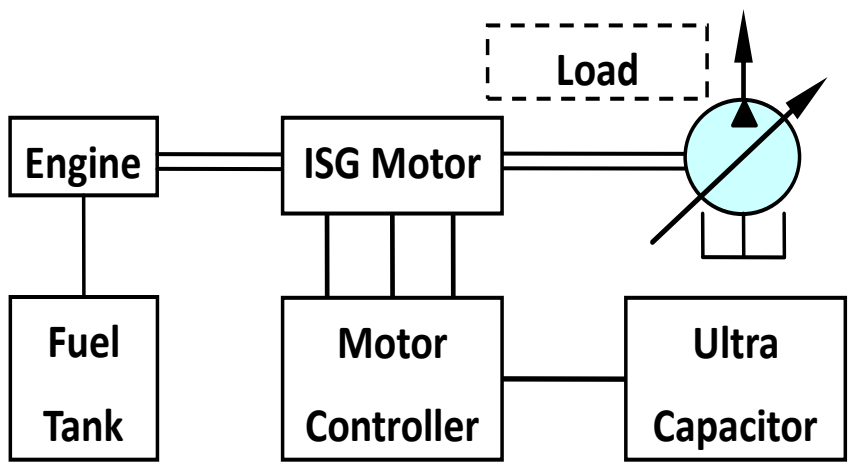

Fig. (2). Structure of the parallel hybrid excavator.

\subsection{Control Strategy Principle}

The instantaneous minimization fuel consumption control strategy is a sort of optimization control strategy [14, 15] which helps to find out all the combination of engine and
ISG motor torque output required by current load. For each combination, one calculates the fuel consumption that would be consumed by the engine denoted as $G_{\text {actual }}$, and the power consumption consumed by ISG motor, then convert this referred power consumption to the effective fuel consumption (denoted as $G_{\text {effective }}$ ) [16-20]. These two parts which includes the converted effective fuel consumption and the actual engine fuel consumption are considered as the power-train instantaneous total fuel consumption, the torque combination which minimizes this total fuel consumption will be adopted as the operating point of the power-train.

The proposed control strategy can be describe as follow:

$$
J_{\min }=\sum_{t=0}^{N} \operatorname{Min}\left\{G_{\text {actual }}(t)+G_{\text {effective }}(t)\right\} \cdot \Delta t
$$

\subsection{Control Strategy Process}

Control strategy process is described as follows:

Calculating the pump real time absorbed torque, which is current load torque of the power-train;

(2) Setting the engine torque target operating area, and according to the current load and state of ultracapacitor charge, defining the reasonable motor torque output range and finding the corresponding relationship between the engine fuel consumption and the motor output torque;

(3) Establishing the corresponding relationship between the motor torque output and the power consumption, and with consideration of step 2 to define the relationship between the engine fuel consumption $G$ to the power consumption $\triangle S O C$;

(4) With the obtained results from Step 3, calculating the effective fuel consumption for replenishing the charge removed from the ultra-capacitor according to engine fuel consumption vs power consumption. With the sum of this effective fuel consumption and actual engine fuel consumption (as current total fuel consumption), the torque combination of the engine and ISG motor which minimize the total fuel consumption will be adopt as the operating point of the power-train.

\subsection{Control Strategy Implementation}

\subsubsection{Load Calculation}

The hydraulic excavator in this research adopts total horsepower and negative flow control technology, the hydraulic pump is duplex axial piston pump. The calculation formula used for pump absorption power is defined as follow:

$P_{p}=p \cdot Q / 60=p \cdot q \cdot n_{e} / 60$

$P_{p}$--- the pump absorbed power, Kw;

$p$--- the pump output pressure, $\mathrm{MPa}$;

$q$--- the pump displacement, L/min; 
$n_{e}$--- the engine speed, rpm;

The relation between the load request power and the pump absorbed power can be described as

$P_{p}=P_{r} \cdot \eta_{m} \cdot \eta_{v}=T_{r} \cdot n_{e} / 9550$

$P_{r}$--- load request power, $\mathrm{Kw}$;

$\eta_{m}$--- the system mechanical efficiency;

$\eta_{v}{ }^{---}$the pump volumetric efficiency;

$T_{r}$--- the load request torque, $\mathrm{Nm}$;

According to (3-4), one obtains the load request torque which is defined as

$T_{r}=0.16 \cdot p \cdot q /\left(\eta_{m} \cdot \eta_{v}\right)$

With the obtained measurements of the pump P-q under different speed and total horsepower control pressure, one can define its corresponding numerical model. With the numerical interpolation principle, one gets the pump current displacement. Then with the application of above equation (5), the load request torque can be calculated.

\subsubsection{Establishment of the Relationship Between the Engine Fuel Consumption and the Motor Output Torque}

The studied engine fuel map is shown in Fig. (3)

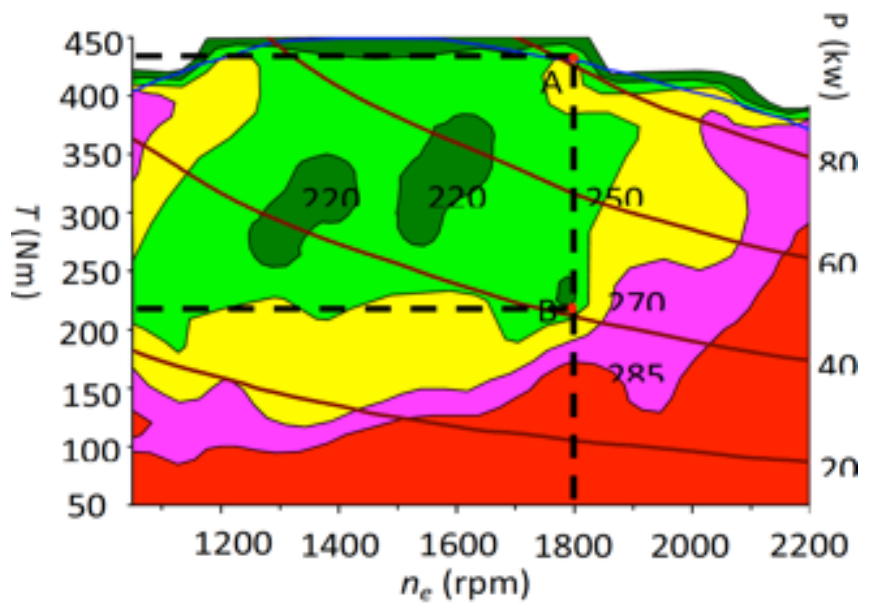

Fig. (3). Engine fuel map.

whose green area represents the high efficiency area of the specific fuel consumption. By considering the intersection points (denotes as A and B) of current engine speed $\left(n_{e}=1800 \mathrm{rpm}\right)$ and high efficiency area of the specific fuel consumption, the engine optimal output torque range can be defined. Then the relationship of torques between the motor, engine and load is described as follow

$T_{m}=T_{r}-T_{e}$

$T_{m}$--- the the motor torque, Nm;

$T_{e}$--- the engine torque $\mathrm{Nm}$;

Moreover, the engine output power can be calculated by the following equation
$N_{e}=T_{e} \cdot n_{e} / 9550$

Thus with consideration of equations $(1,6)$, one obtains the engine fuel consumption curve under different motor output torque. The corresponding curve is illustrated in Fig. (4).

\subsubsection{Determination of the Relationship Between the Engine Fuel Consumption and $\triangle S O C$}

With the established relationship between the motor torque and $\triangle S O C$, the state of ultra-capacitor charge which is denoted as $s o c$ can be calculated as follow

soc $=E_{C} / E_{R}=0.5 C \cdot V_{C}^{2} / 0.5 C \cdot V_{R}^{2}=V_{C}^{2} / V_{R}^{2}$

$E_{c}$--- the current ultra-capacitor energy, J;

$E_{r}$--- the full charged capacitor energy, J;

$C$--- the capacity, F;

$V_{c}$--- the capacitor voltage under open-loop circuit, U;

$V_{r}$--- the rated voltage of capacitor, $\mathrm{U}$;

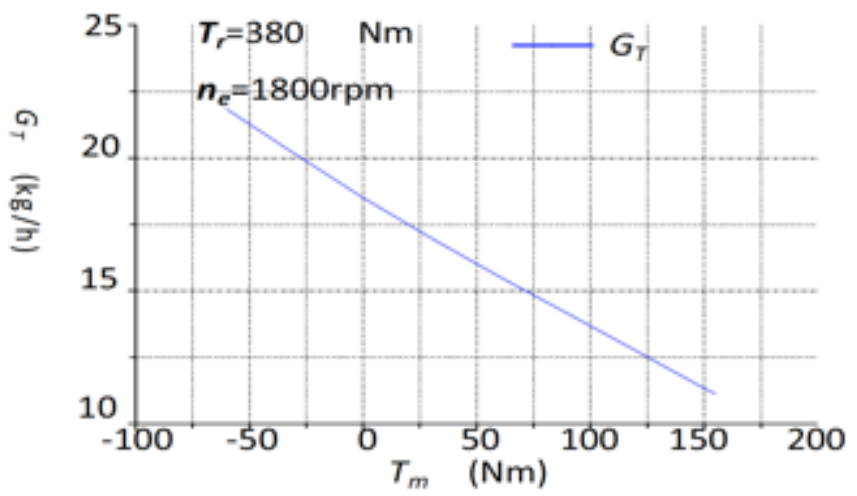

Fig. (4). $G_{T} v s T_{m}$.

Within a sampling time step, the variation value of $\triangle S O C$ which is caused by the motor output is described as follow

$\Delta s o c=T_{m} \cdot n_{e} \cdot \eta_{e / g} \cdot \Delta t /\left(9550 \cdot \eta_{d s c / c} \cdot E_{R}\right)$

$\eta_{e}{ }^{---}$the motor electric efficiency;

$\eta_{g}$--- the motor generation efficiency;

$\Delta t$--- the sampling time step;

$\eta_{d s c}$--- the ultra-capacitor discharge efficiency;

$\eta_{c}$--- the capacitor charge efficiency;

By considering the subsection 3.3.2 and equation (9), one obtains the engine fuel consumption curve with the normalized value $\triangle \mathrm{SOC}$. This corresponding result can be illustrated in Fig. (5).

\subsubsection{Calculation of the Current Instantaneous Fuel Consumption}

In order to maintain the balance of ultra-capacitor charge, one should ensure that the charge removed away from the capacitor should be equally replenished, which means 


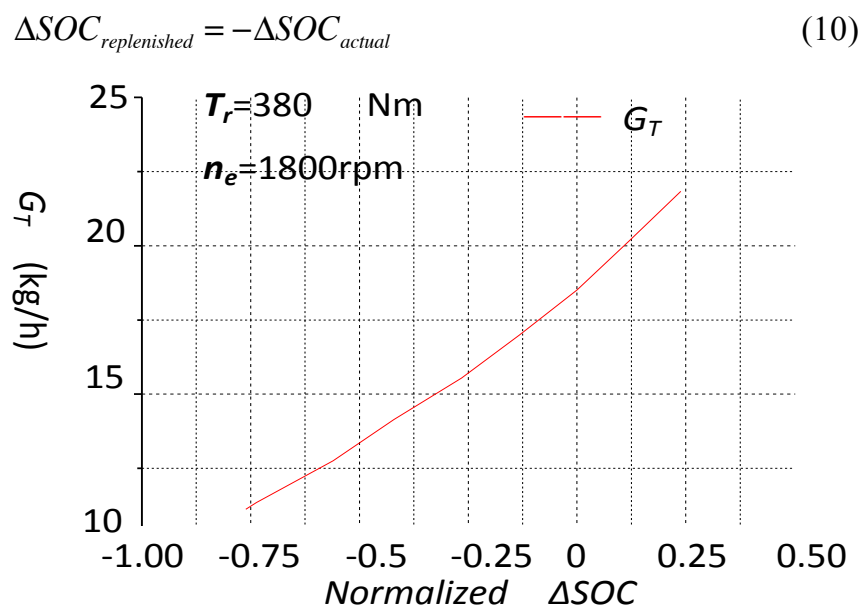

Fig. (5). $G_{T} v S \triangle S O C$.

Then with the application of the engine fuel consumption

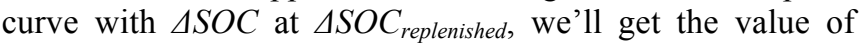
total engine fuel consumption (see $G_{\text {current }}$ in Fig. 6), this is the fuel consumption.

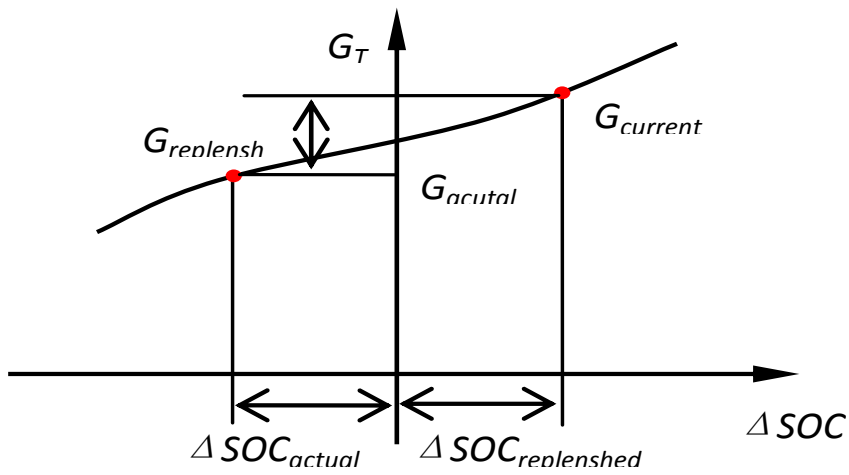

Fig. (6). Calculating fuel consumption.

\section{SIMULATION AND EXPERIMENTAL TEST}

\subsection{Parallel Hybrid System Modelling}

According to the architecture of power system shown in Fig. (2), a simulation model of parallel hybrid hydraulic excavator has been established, as shown in Fig. (7). The relative mathematical models are as follows.

\subsubsection{Engine Model}

The purpose of this research is to improve engine operating point and fuel efficiency, so a mean value engine model is adopt. Engine steady governing model can be described as follow:

$T_{e}\left(n_{e}, \alpha\right)=k_{1}+k_{2} \sin k_{3}\left(n_{e}+k_{4}\right)+1 / \alpha\left(\alpha+k_{5} n_{e}+k_{6}\right)$

$T_{e}\left(n_{e}, \alpha\right)$--- the engine steady torque out-put, Nm;

$n_{e}$--- the engine speed, rpm;

$\alpha$--- the throttle opening;

$k_{1} \sim k_{6}---$ the fitting coefficient;
Equation (11) can be obtained via curve-fitting methodology based on steady experimental data.

In most of time, the engine works under the unsteady state, in order to reflects its dynamic characteristics, engine dynamic model is needed, this model can be described as follow

$T_{e d}\left(n_{e}, \alpha\right)=T_{e}\left(n_{e}, \alpha\right)-J_{e} \dot{n}_{e}-C_{e} n_{e}$

$T_{e d}\left(n_{e}, \alpha\right)$--- dynamic engine torque output, $\mathrm{Nm}$;

$J_{e}$--- the equivalent engine rotational inertia, $\mathrm{Kg} \cdot \mathrm{m}^{2}$;

$C_{e^{---}}$the viscous damping coefficient;

Engine fuel consumption model is described as follow

$m_{\text {fuel }}=k \int \eta_{\text {fuel }} \cdot M_{e}\left(n_{e}, \alpha\right) \cdot n_{e} d t$

$m_{\text {fuel }}{ }^{---}$the engine fuel consumption,

$\eta_{\text {fuel }}$--- the fuel efficiency

it can be obtained via looking up fuel efficiency table using interpolation method when engine speed and output torque is determined.

\subsubsection{ISG Motor Model}

As the important energy transformation device, the energy transformation efficiency and dynamic characteristic of ISG motor were focused on in the research. ISG motor dynamic model can be described as follow:

$T_{m d}=T_{m s} \cdot \frac{1}{T s+1}$

$T_{m d}$--- the ISG motor dynamic torque output, Nm;

$T_{m s}$--- the ISG motor steady torque output, Nm;

$T$--- the system time constant;

$s$--- the Laplace transform variable;

ISG motor efficiency model $\eta_{m}=\eta_{m}\left(n, T_{m d}\right)$ can be obtained via interpolation method.

\subsubsection{Ultra Capacitor Model}

$V$ stands for ultra capacitor operating voltage, set, at some point ultra capacitor operating voltage is $V(n)$, the next point ultra capacitor operating and $V(n+1)$ can be described as follow:

$V(n+1)=V(n)-I \frac{\Delta t}{C}$

$I$--- the ultra capacitor operating current, A;

$C$--- the ultra capacitor capacitance, $\mathrm{F}$;

$\Delta t$--- the time step;

Ultra capacitor state of charge (soc) can be calculated by Equation (8). 


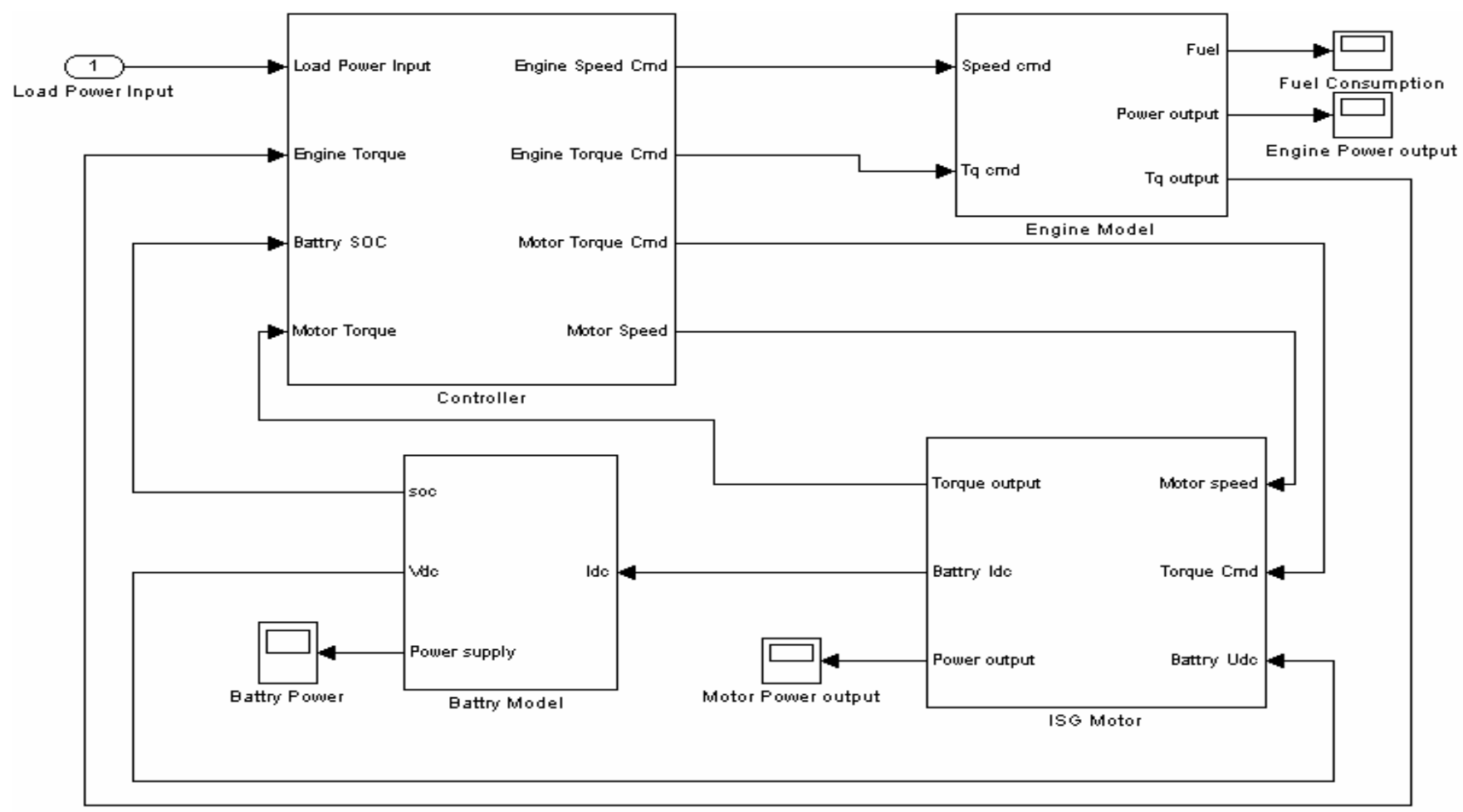

Fig. (7). Power system model of hybrid excavator.

Ultra capacitor energy output $E$ can be calculated by the follow equation.

$E=0.5 C\left(V_{2}^{2}-V_{1}^{2}\right)$

$V_{1}$--- the capacitor starting operating voltage, $\mathrm{U}$;

$V_{2}$--- the capacitor terminated operating voltage, $\mathrm{U}$.

\subsection{Experimental Environment Introduction}

To validate the instantaneous minimum fuel control strategy, comparing tests have been implemented on a selfdeveloped hydraulic excavator parallel hybrid power-train test bench (with or without the hybrid power-train condition). Compared with a commercial available $20 \mathrm{t}$ excavator, the used self-developed test bench equips a same hydraulic system and a electro-hydraulic technology was adopted for loading. The corresponding entire platform structure can be illustrated in Fig. (8). Fig. (9) is the picture of the test platform.

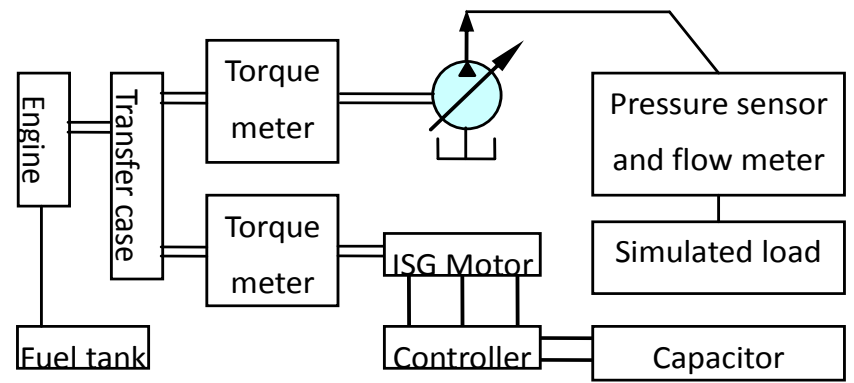

Fig. (8). Architecture of test platform.

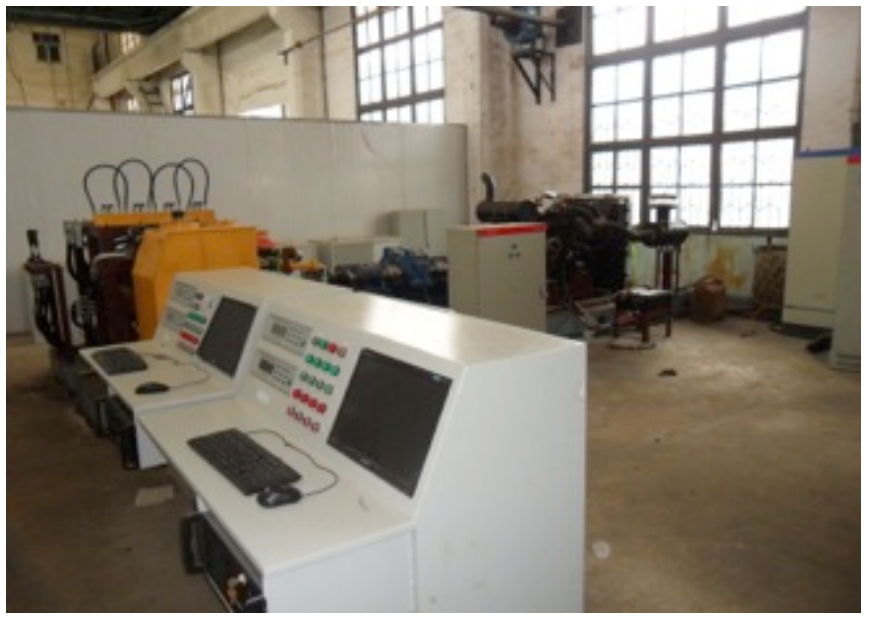

Fig. (9). Picture of test platform.

In order to simulate the real-time excavator working experimental conditions, a load spectrum which is acquired from actual excavator mining operations is implemented on the self-development test bench via the referred load simulation system with electro-hydraulic technology.

Their corresponding experimental results which are experimental under the conditions of engine speed ne $=1800$ $\mathrm{rpm}$ and the power range $(50,70)(\mathrm{kw})$ are illustrated in Fig. (10) (test group 1) and Fig. (11) (test group 2). The subfigure (a) represents the power outputs with and without hybrid power-train under the function of the same external measuring load. The green curve shows the load power variation, the blue one stands for the engine power of conventional mode (which means the only engine drive, without the assistance of the ISG motor), and the red and black curves represent respectively the output power of 
engine and motor under the proposed hybrid power-train mode; sub-figure (b) illustrates the soc variation of ultracapacitor; sub-figure (c) stands for the contrast engine fuel consumption curves.

(a) Power Curve of the load and the power source

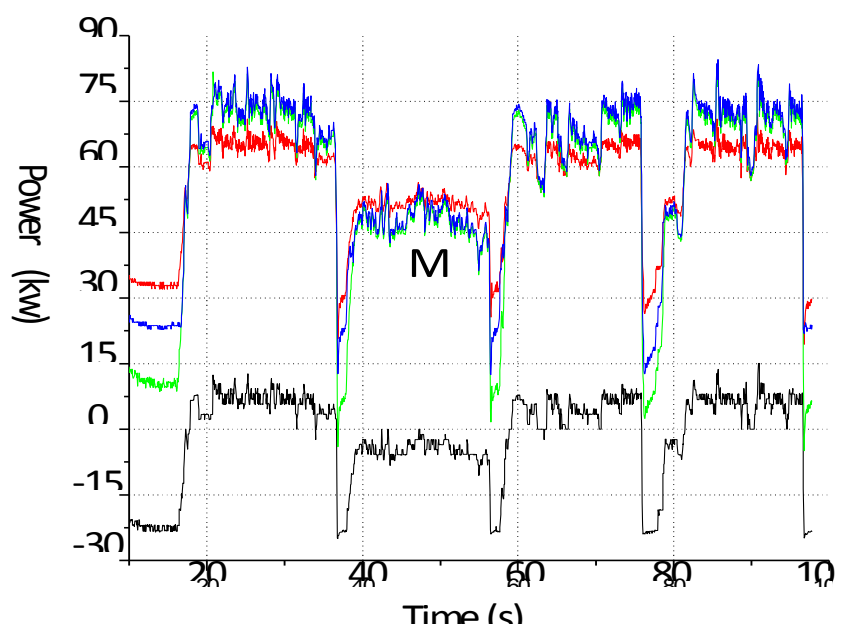

Load Power —_ Engine Power (un-optimized) __ Engine Power (optimized) — Motor Power of Hybrid Mode

(b) Ultra state of ultra-capacitor charge

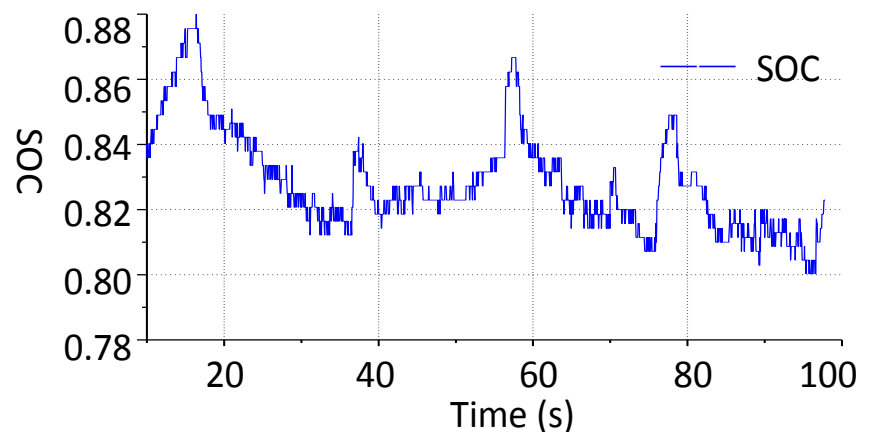

(c) Engine fuel consumption contrast

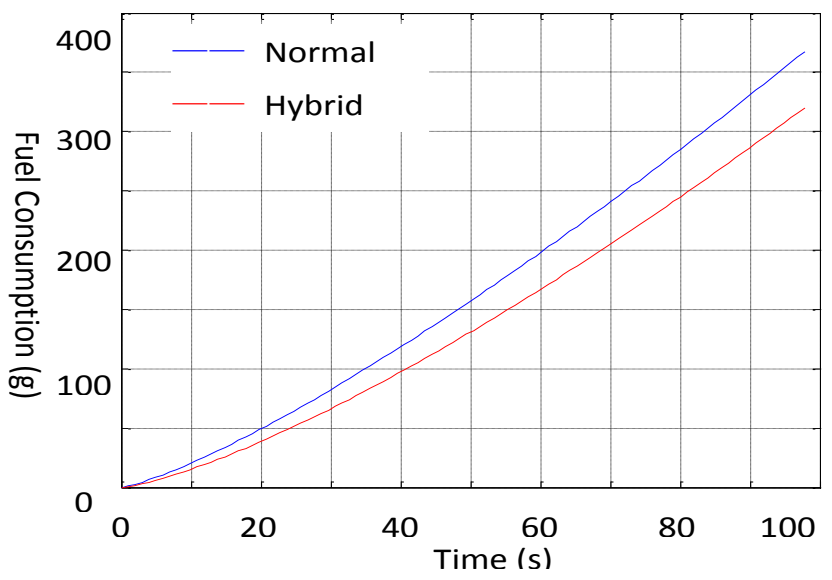

Fig. (10). Experimental result of test group 1.

For test group 1 illustrated in Fig. (8) whose initial soc value is 0.836 , its terminal soc value is 0.80 after and after 4 complete operating cycles. In general, it decreases slightly with a reasonable balance around the vicinity of 0.82 and demonstrates that the proposed minimization instantaneous control strategy can maintain a balanced ultra-capacitor soc efficiently.

(a) Power Curve of the load and the power source

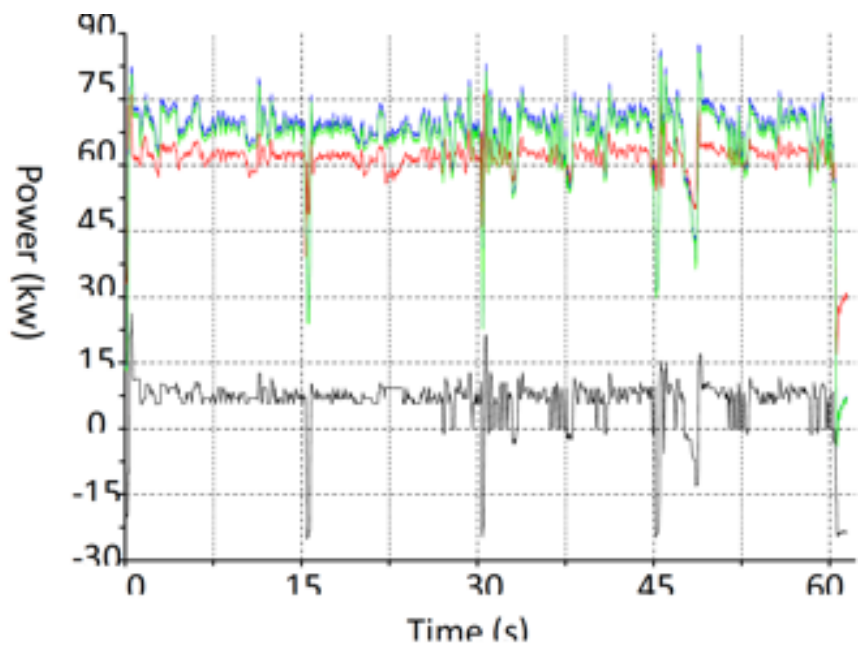

Load Power — Engine Power (un-optimized) —_ Engine Power (optimized) — Motor Power of Hybrid Mode

(b) Ultra state of ultra-capacitor charge

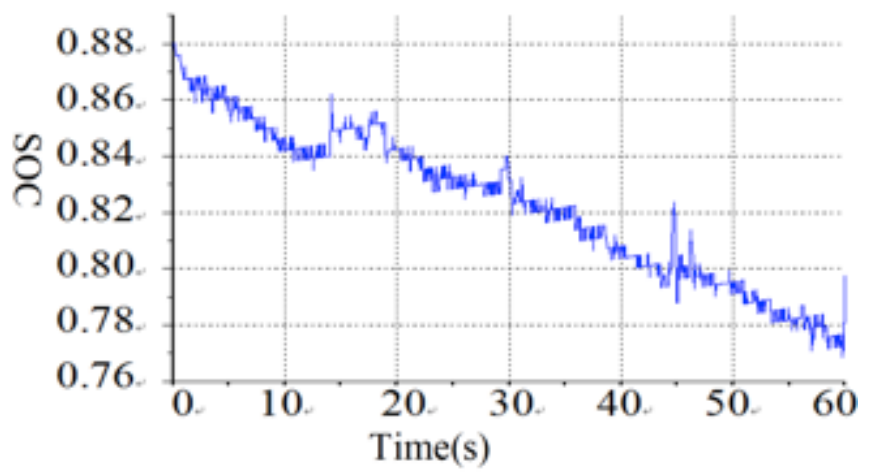

(c) Engine fuel consumption contrast

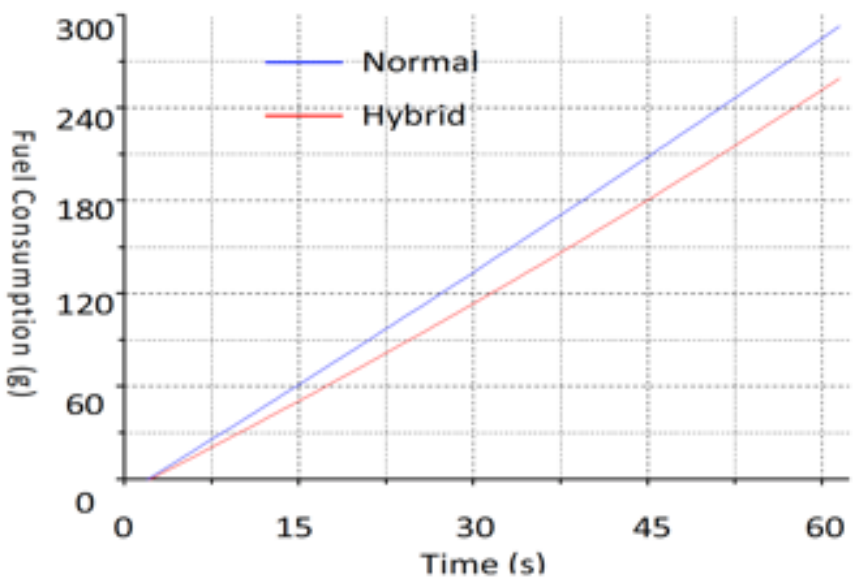

Fig. (11). Experimental result of test group 2

For test group 2, the considered soc value decreases a little more by comparing the result in test group 1 , because 
the experimentation is carried on a modified control weight by considering the equation (2), in which more emphasis has been put on minimizing the value of $G_{\text {actual }}$. The removed soc is calculated and anticipated which can be replenished in the near future.

Fig (12) shows the fuel saving rate of each test group for group1 and group2. For test group1, the engine fuel consumption under hybrid mode is $320 \mathrm{~g}$, and that of conventional mode is $368 \mathrm{~g}$, the former has $13.04 \%$ fuel saving than the latter; For test group2, the engine fuel consumption of hybrid mode is $255 \mathrm{~g}$, and that of conventional mode is $290 \mathrm{~g}$, the former is $12.07 \%$ fuel saving than the latter. From these test groups, it can be concluded that the hybrid mode is about $12.55 \%$ fuel saving on average, which demonstrates that the proposed instantaneous control strategy has good fuel-saving effect.

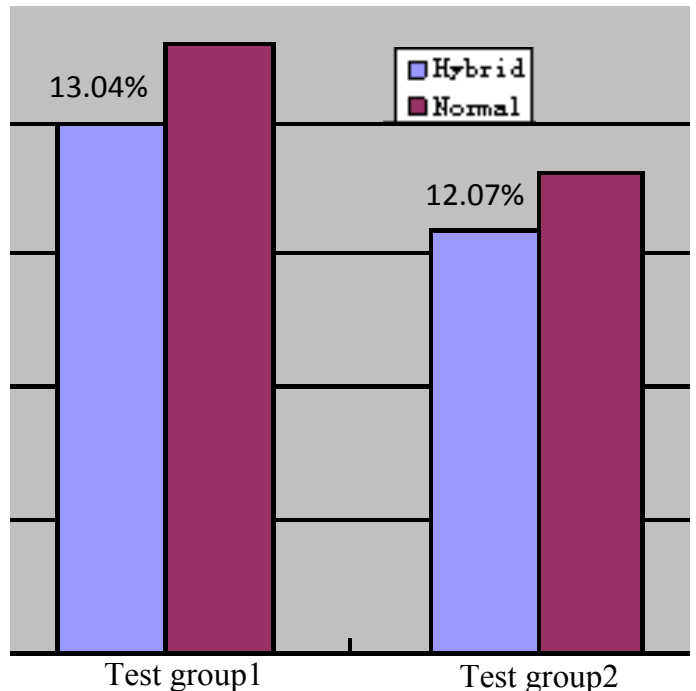

Fig. (12). Fuel Consumption and Fuel Saving Rate

\section{CONCLUSION}

In this paper, an instantaneous minimization fuel consumption control strategy is proposed for a $20 \mathrm{t}$ parallel hybrid hydraulic excavator. In order to validate this proposed control strategy, contrast experimental tests have been undertook on the self-developed medium hydraulic excavator parallel hybrid power-train test bench with application of a pre-acquired load spectrum measuring from the actual excavator mining operations. Experimental results show that the proposed control strategy ensuring the remarkable engine fuel saving of $12.55 \%$.

\section{ABOUT THE AUTHORS}

First Author Xu Miao, College of Mechanical Science and Engineering, Ph.D. The author's major is Mechatronic Engineering..

Second Author Zhao Dingxuan, Yangtze river scholars Distinguished Professor, Doctoral supervisor of Jilin University of Mechanical Technology. The author is majored in Construction vehicle mechatronics.
Third Author Ni Tao, professor of Jilin University, The author's major is Virtual reality technology.

\section{CONFLICT OF INTEREST}

The authors confirm that this article content has no conflict of interest.

\section{ACKNOWLEDGEMENTS}

This work was financially supported by the National High-tech R\&D Program (863 Program)(2009AA044403).

\section{REFERENCES}

[1] Q. Xiao, "Control Strategy and Parameter Matching of Hybrid System in Hydraulic Excavator," Zhejiang University, 2008.

[2] A. Sciarretta, M. Back, and L. Guzzella, "Optimal control of parallel hybrid electric vehicles," IEEE Transactions on Control Systems Technology, vol. 12, no. 3, pp. 352-363, 2004.

[3] N.J. Schouten, M.A. Salman, and N.A. Kheir, "Fuzzy logic control for parallel hybrid vehicles," IEEE Transactions on Control Systems Technology, vol. 10, no. 3, pp. 460-468, 2002.

[4] B. Seta, G. Metin, and D.J. Goering, "A novel model validation and estimation approach for hybrid serial electric vehicles," IEEE Transactions on Vehicular Technology, vol. 56, no. 4, pp. 485-497, 2007.

[5] X. Lin, S. X. Pan, and D. Wang, "Dynamic simulation and optimal control strategy for a parallel hybrid hydraulic excavator," Journal of Zhejiang University: Science A, vol. 9, no. 5, pp. 624-632, 2008.

[6] M. Ehsani, Y. Gao, S.E. Gay, A. Emad, Modern Electric, Hybrid Electric, and Fuel Cell Vehicles Fundamentals, Theory, and Design, $2^{\text {nd }}$ ed., China Machine Press: Beijing, 2008, pp. 156-188.

[7] M. Kagoshima, T. Sora, and M. Komiyam, "Development of hybrid power train control system for excavator," JSAE Annual Congress, vol. 86, pp. 1-6, 2003.

[8] T. Akira, N. Takao, Y. Hideaki, "Development of the electro hydraulic actuator system on hybrid excavator," JSAE Annual Congress, vol. 86, pp. 7-12, 2003.

[9] N. Takao, I. Etsujiro, and K. Masayuki, "Power simulation on the actual operation in hybrid excavator," JSAE Annual Congress, vol. 86, pp. 13-18, 2003.

[10] S. Naoki, N. Takao, I. Etsujiro, H. Yoshimatu, and M. Uejima, "Swing system development of construction machinery," JSAE Annual Congress, vol. 56, pp. 7-12, 2004.

[11] Y.T. Zhang, Research on Energy Saving of Hydraulic Excavator Based on Hybrid and Regeneration, Hangzhou: Zhejiang University, 2006.

[12] D.Y. Wang, Research on the power-train hybridization and parameter matching of hydraulic excavator, Hangzhou: Zhejiang University, 2009.

[13] Q.H. He, C.S. Liu, J. Gong, "Research on structure and control strategy of a parallel hybrid system in hydraulic excavator," Chinese Journal of Construction Machinery, vol. 9, no. 1, pp. 4853, 2011.

[14] V.H. Johnson, K.B. Wipke, and D.J. Rausen, "HEV control strategy for real-time optimization of fuel economy and emissions," SAE Paper 2000, 2000-01-1543.

[15] J.Y. Park, Y.K. Park, and J.H. Park, "Real-Time Power-train Control Strategy for Series-Parallel Hybrid Electric Vehicles," SAE Paper, 2007, 2007-01-3472.

[16] G. Paganelli, Y. Guezennec, and G. Rizzoni, “Optimizing Control Strategy for Hybrid Fuel Cell Vehicle,” SAE Paper, 2002-01-0102.

[17] C. Musardo, G. Rizzoni, and B. Staccia, "A-ECMS: An Adaptive Algorithm for Hybrid Electric Vehicle Energy Management," In: Proceedings of the $44^{\text {th }}$ IEEE Conference on Decision and Control, and the European Control Conference ,2005. 
[18] V. Sezer, V. Klç, and M. Yldrm, "Maximizing Overall Efficiency Strategy (MOES) for Power Split Control of a Parallel Hybrid Electric Vehicle," SAE Paper, 2008-01-2682.

[19] B. Jeanneret, and T. Markel, "Adaptive Energy Management Strategy for Fuel Cell Hybrid Vehicles," SAE Paper, 2004-011298.
[20] G. Paganelli, S. Delprat, and T.M Guerra, "Equivalent Consumption Minimization Strategy for Parallel Hybrid Powertrains," In: Proceedings of the $55^{\text {th }}$ IEEE Conference on Vehicular Technology, vol. 4, pp. 2076-2081, 2002.

(C) Miao et al.; Licensee Bentham Open.

This is an open access article licensed under the terms of the Creative Commons Attribution Non-Commercial License (http://creativecommons.org/licenses/by-nc/3.0/) which permits unrestricted, non-commercial use, distribution and reproduction in any medium, provided the work is properly cited. 